\title{
Hyponatremia during treatment with the clozapine- amisulpride combination: a suspected association and improvement with dose reduction
}

\author{
Mehmet Hamdi Orum ${ }^{1}{ }^{\oplus}$, Behice Han Almis ${ }^{2 \oplus}$ \\ ${ }^{1}$ Adiyaman University, Faculty of Medicine, Department of Psychiatry, Adiyaman - Turkey \\ ${ }^{2}$ Adiyaman University Training and Research Hospital, Department of Psychiatry, Adiyaman - Turkey
}

\begin{abstract}
Clozapine is the only antipsychotic that is effective in treatment-resistant schizophrenia, but in certain cases its effectiveness is limited. To improve efficacy, clinicians commonly augment clozapine with another antipsychotic. Clozapine has serious side effects due to its receptor profile. The second antipsychotic to be added to clozapine should be less likely to cause these side effects. Amisulpride may be a suitable medication for clozapine-augmentation therapy. However, side effects may also occur in this combination. Here we report for the first time in a 31-year-old male patient diagnosed with schizophrenia who presented with hyponatremia following the addition of amisulpride to clozapine and the improvement of this condition with dose reduction. When adverse effects are non-fatal or can be controlled by supportive treatments, dose reduction may be more useful than discontinuing the drug. In conclusion, we should not prematurely change the combination of clozapine and amisulpride in treatment-resistant schizophrenia.
\end{abstract}

Keywords: Amisulpride, clozapine, hyponatremia, side effect

\section{INTRODUCTION}

Clozapine is the only antipsychotic for cases, which there is convincing evidence of efficacy in strictly-defined treatment-resistant schizophrenia, but in such cases its effectiveness is still limited, with $30-40 \%$ of patients showing an inadequate response to the drug. In an attempt to improve efficacy, clinicians commonly augment clozapine with another antipsychotic (1). Clozapine has side effects such as agranulocytosis, seizures, and cardiomyopathy that can result in death. Other potentially serious side effects of clozapine are weight gain and constipation (2). Therefore, the second antipsychotic to be added to clozapine should be less likely to cause the same side effects. In this respect, amisulpride may be a suitable medication for clozapine-augmentation therapy. On the other hand, there are potential risks that this combination may cause. Cardiac effects, tremor, akathisia, and bradykinesia are reported side effects of this combination (3). Although there are cases of clozapine(4) and amisulpride-induced hyponatremia (5), no case studies have been reported where hyponatremia is associated with the dose of these two drugs combination.

\section{CASE}

A 31-year-old male patient with a 10-year history of schizophrenia presented to our outpatient unit with

How to cite this article: Orum MH, Han Almis B. Hyponatremia during treatment with the clozapine-amisulpride combination: a suspected association and improvement with dose reduction. Dusunen Adam The Journal of Psychiatry and Neurological Sciences 2019;32:171-4.

Correspondence: Mehmet Hamdi Orum, Adiyaman University, Faculty of Medicine, Department of Psychiatry, Adiyaman - Turkey

Phone: +90 41621610 15-11 86 E-mail: mhorum@hotmail.com

Received: November 17, 2018; Revised: December 07, 2018; Accepted: December 18, 2018 
symptoms of cognitive impairment, fluctuation of attention, reduced awareness of the environment, slowed movement, and irritability. He was admitted to the psychiatric inpatient unit with a diagnosis of schizophrenia plus delirium according to the DSM-5 (6). The patient had been using clozapine $600 \mathrm{mg} /$ day for more than one year, and amisulpride had been added to the treatment about two months ago, subsequently increased to $800 \mathrm{mg} /$ day a month ago due to an insufficient response of psychotic symptoms such as delusion and withdrawing. The evaluation made in the inpatient unit revealed a normal level of fasting blood glucose, protein level, and lipid profile. Laboratory analysis showed a serum sodium level of $119 \mathrm{mmol} / \mathrm{L}$, a potassium level of $3.9 \mathrm{mmol} / \mathrm{L}$, and a chloride level of $93 \mathrm{mEq} / \mathrm{L}$. The extracellular volume was normal and the urinary sodium level was $41 \mathrm{mEq} / \mathrm{L}$. Thyroid function tests revealed normal results. Chest X-ray, electrocardiogram, and renal ultrasonography gave normal results. The patient used no drugs other than clozapine and amisulpride. He had no systemic disease such as hypertension or diabetes mellitus. He used to smoke one and a half pack a day and had no history of alcohol or substance abuse. The family stated that there had been no change in smoking, dietary habits and fluid intake in recent days and he had no family history. A diagnosis of euvolemic hyponatremia, attributed to the syndrome of inappropriate secretion of antidiuretic hormone (SIADH), was made. Supportive treatment was initiated and it was thought that high doses or rapid dose escalation of the antipsychotics might have caused hyponatremia. The doses of both clozapine and amisulpride were decreased to $400 \mathrm{mg}$ /day. Four days later, the serum sodium level reached $138 \mathrm{mEq} / \mathrm{L}$ and stayed within normal limits at one-month follow-up. Hyponatremia-related symptoms disappeared, and his psychotic symptoms partially improved with this combination compared to the time of admission. The patient and his family were warned about drug-induced hyponatremia. At follow-up, he did not report hyponatremia with a combination of clozapine $400 \mathrm{mg} /$ day and amisulpride $400 \mathrm{mg}$ /day. On Naranjo's adverse drug reaction probability scale (NADRPS), the patient had a score of 6 (7). Written informed consent was taken from the patient and his family in order to publish their data.

\section{DISCUSSION}

When patients diagnosed with treatment-resistant schizophrenia receiving clozapine do not respond sufficiently, the choice of amisulpride for augmentation is reasonable because it has a receptor profile complementary to that of clozapine (3). International guidelines report only certain treatment options for treatment-resistant schizophrenia and do not suggest a hierarchical order. Thus, the combination of clozapine and amisulpride continues to be used in the absence of evidence to the contrary (8). We undertook a literature review regarding the side effects of this combination being used in treatment-resistant schizophrenia, searching PubMed using the medical subject headings clozapine, amisulpride, and hyponatremia to identify reported diagnoses of hyponatremia following the augmentation of clozapine with amisulpride in patients diagnosed with treatmentresistant schizophrenia, but these search terms did not match any documents. In this case of a young male schizophrenia patient with hyponatremia following the addition of amisulpride to clozapine, we report for the first time the improvement of the side effect with dose reduction. Since hyponatremia developed after the addition of amisulpride, the latter can be considered responsible for the side effect, and many physicians may immediately discontinue its use. This may be one of the reasons why there are no previous case reports on this issue. Although there is no case in the literature reporting hyponatremia with this combination of drugs, there are cases dealing with clozapine and amisulpride separately. Our patient was evaluated as a case of hyponatremia due to a combination of clozapine and amisulpride. Due to the temporal relationship between them, the side effect began with the addition of the second drug and completely resolved after reducing the dose of the drug. Other possible causes of hyponatremia, such as volume depletion, hypothyroidism, diuretic abuse, and vomiting were excluded.

In 2010, Mannesse et al. (9) published a case-control study related to VigiBase, the World Health Organization's global database of individual case safety reports. Although spontaneous reporting systems include various types of bias, confounding and misclassification, this study suggested that the association of antipsychotics and reports of hyponatremia did not statistically differ by chemical class or affinity for dopamine type 2 (D2) and serotonin (5-Hydroxytryptamine, 5-HT) type $2 \mathrm{~A}$ receptors. In their study, 19 cases using amisulpride associated with hyponatremia and 141 cases using clozapine were reported. There were no data about the combination of these drugs. These cases were presented based on selfreports, not on literature knowledge, so the study results may not be reliable. Ali and Bazzano (10) conducted a systematic review of case reports of hyponatremia 
associated with the use of second-generation antipsychotics in patients with schizophrenia searching MEDLINE. They did not find any cases about an association of amisulpride and hyponatremia, while one case was found with clozapine, reported in 1992 (4). However, Collins and Anderson (5) presented a case with two episodes of hyponatremia secondary to successive treatments with risperidone and amisulpride in a female patient with paranoid schizophrenia. Some hypotheses have been proposed to explain the mechanism of hyponatremia associated with antipsychotics. As with other psychotropic medications, it is suspected that second-generation antipsychotics can induce hyponatremia by either stimulating antidiuretic hormone release from the brain or enhancing antidiuretic hormone activity in the kidneys. Studies about neurotransmitters suggest a long-term D2 receptor blockade leading to D2 receptor supersensitivity, which in turn results in $\mathrm{ADH}$ release, antipsychotic-induced hypotension leading to $\mathrm{ADH}$ release through baroreceptor reflex, and serotoninmediated effects on central 5-HT2 and 5-HT1c receptors stimulating $\mathrm{ADH}$ secretion $(11,12)$. Clozapine has high affinity for serotonin receptors and amisulpride for D2 receptors (2). We have interpreted these cases as a cooperative effect of dopamine and serotonin. It was found that the level of sodium was significantly different in patients who were taking antipsychotics compared to those who did not, no significant correlation between drug dose and hyponatremia was found (13). On the other hand, some side effects of antipsychotics have been reported to be dose-dependent (14). So, in our case, high doses or cumulative effects of drug mechanisms causing hyponatremia and rapid dose increase might have led to its manifestation.

The NADRPS score indicates a probable association between drug use and side effect (7). When hyponatremia occurs, the patient's general medical condition should be reassessed and other organic conditions that may cause hyponatremia should be excluded. The drug dose can be reduced or the drug can be changed (12). In our patient, when the drug dose was reduced and supportive treatment started, the hyponatremia disappeared. The World Health Organization (WHO) defines as 'probable' the causation of an event or laboratory test abnormality if it occurs in a reasonable temporal relationship with the drug intake (15). The WHO also requires that this relationship cannot reasonably be explained clinically by disease or other drugs or response to withdrawal, while rechallenge is not necessary. Factors influencing compliance with medication in patients with psychiatric disorders include patient-related influences, physicianrelated variables, factors related to the patient's environment, treatment-related factors, and side effects. The influence of side effects has been demonstrated in patients' noncompliance with treatment. Sometimes, despite the side effects, some patients continue to be exposed to the drug. The level of functioning of the patients' relatives and psychiatric or physical diseases they may have should be taken into consideration (16). For these reasons, we have informed the patient and his relatives about this side effect.

In daily routine of some physicians, the management of drug-induced SIADH often leads to the discontinuation of the suspected agent. In cases of adverse effects that are non-fatal or can be controlled by supportive treatments, dose reduction may be more useful than discontinuing the drug. In cases where the drug option is very limited, such as treatment-resistant schizophrenia, we do not want to lose the combination of clozapine and amisulpride. Further systemic research should be conducted with respect to clozapine and amisulpride combination-associated hyponatremia and its improvement with dose reduction to provide a greater understanding of both its prevalence and etiology.

\begin{tabular}{|l|l|l|}
\hline \multicolumn{4}{|l}{ Contribution Categories } & Author Initials \\
\hline \multirow{4}{*}{ Category 1} & Concept/Design & M.H.O., B.H.A. \\
\cline { 2 - 3 } & Literature review & M.H.O., B.H.A. \\
\cline { 2 - 3 } & Data analysis/Interpretation & M.H.O., B.H.A. \\
\cline { 2 - 3 } & Case follow-up (if applicable) & M.H.O., B.H.A. \\
\hline \multirow{3}{*}{ Category 2} & Drafting manuscript & M.H.O., B.H.A. \\
\cline { 2 - 3 } & Critical revision of manuscript & M.H.O., B.H.A. \\
\hline \multirow{2}{*}{ Category 3} & Final approval and accountability & M.H.O., B.H.A. \\
\hline \multirow{3}{*}{ Other } & Technical or material support & M.H.O., B.H.A. \\
\cline { 2 - 3 } & Supervision & N/A \\
\hline
\end{tabular}

Informed Consent: Written informed consent was obtained from the patient for the publication of the case report.

Peer-review: Externally peer-reviewed.

Conflict of Interest: No conflict of interest was declared by the authors.

Financial Disclosure: The authors declared that this study has received no financial support.

\section{REFERENCES}

1. Chakos M, Lieberman J, Hoffman E, Bradford D, Sheitman B. Effectiveness of second-generation antipsychotics in patients with treatment-resistant schizophrenia: a review and metaanalysis of randomized trials. Am J Psychiatry 2001; 158:518-526. 
2. Kampf P, Agelink W, Mass R, Jahn H, Schafer I, Naber D. Amisulpride in addition to clozapine: A retrospective study indicates improved efficacy and good tolerability. German J Psychiatry 2003; 6:64-68.

3. Barnes TRE, Leeson V, Paton C, Marston L, Osborn DP, Kumar R, Keown P, Zafar R, Iqbal K, Singh V, Fridrich P, Fitzgerald Z, Bagalkote H, Haddad PM, Husni M, Amos T. Amisulpride augmentation of clozapine for treatment-refractory schizophrenia: a double-blind, placebo-controlled trial. Ther Adv Psychopharmacol 2018; 8:185-197.

4. Ogilvie AD, Croy MF. Clozapine and hyponatremia. Lancet 1992; 340:672.

5. Collins A, Anderson J. SIADH induced by two atypical antipsychotics. Int J Geriatr Psychiatry 2000; 15:282-283.

6. American Psychiatric Association. Diagnostic and Statistical Manual of Mental disorders Fifth ed. (DSM-5), Washington, DC: American Psychiatric Publ., 2013.

7. Kose S, Akin E, Cetin M. Adverse drug reactions and causality: The Turkish version of Naranjo Adverse Drug Reactions Probability Scale. Psychiatry and Clinical Psychopharmacology 2017; 27:205-206.

8. Barnes TRE, Leeson V, Paton C, Marston L, Osborn DP, Kumar R, Keown P, Zafar R, Iqbal K, Singh V, Fridrich P, Fitzgerald Z, Bagalkote H, Haddad PM, Husni M, Amos T. Amisulpride augmentation of clozapine for treatment-refractory schizophrenia: a double-blind, placebo-controlled trial. Ther Adv Psychopharmacol 2018; 8:185-197.
9. Mannesse CK, van Puijenbroek EP, Jansen PA, van Marum RJ, Souverein PC, Egberts TC. Hyponatraemia as an adverse drug reaction of antipsychotic drugs: a case-control study in VigiBase. Drug Saf 2010; 33:569-578.

10. Ali SN, Bazzano LA. Hyponatremia in association with secondgeneration antipsychotics: A systematic review of case reports. Ochsner J 2018; 18:230-235.

11. Gandhi S, McArthur E, Reiss JP, Mamdani MM, Hackam DG, Weir MA, Garg AX. Atypical antipsychotic medications and hyponatremia in older adults: a population-based cohort study. Can J Kidney Health Dis 2016; 3:21.

12. Orum MH, Kalenderoglu A, Egilmez OB, Ozen ME, Kapici Y. Hyponatremia associated with repeated use of sodium valproate. Psychiatry and Behavioral Sciences 2018; 8:93-94.

13. Meulendijks D, Mannesse CK, Jansen PA, van Marum RJ, Egberts TC. Antipsychotic-induced hyponatremia: A systematic review of the published evidence. Drug Saf 2010; 33:101-114.

14. Orum MH, Han-Almis B, Karaca HT. Rapid onset of pedal edema associated with risperidone in two male patients: Simultaneous clinical cases. Journal of Mood Disorders 2017; 7:237-240.

15. Meyboom RH, Hekster YA, Egberts AC, Gribnau FW, Edwards IR. Causal or casual? The role of causality assessment in pharmacovigilance. Drug Saf 1997; 17:374-389.

16. Ozen ME, Orum MH, Kalenderoglu A. Difficult patient in psychiatry practice: a case-control study. Adiyaman Universitesi Saglik Bilimleri Dergisi 2018; 4:1064-1073. (Turkish) 